\title{
Prevalence of grade 1, 2 and 3 thinness is associated with lower socio-economic status in children in Shanghai, China
}

\author{
Chang Chen ${ }^{1} \dagger$, Zhijuan Jin ${ }^{2,3} \uparrow$, You Yang ${ }^{2}$, Fan Jiang ${ }^{2,3}$, Xingming Jin ${ }^{2}$, Hong Huang ${ }^{3, *}$ \\ and Shijian Liu $1,3, *$ \\ 'Department of Clinical Epidemiology, Pediatric Translational Medicine Institute, Shanghai Children's Medical \\ Center, School of Public Health and School of Medicine, Shanghai Jiaotong University, 1678 Dongfang Road, \\ Shanghai 200127, People's Republic of China: ${ }^{2}$ Department of Developmental and Behavioral Pediatrics, Shanghai \\ Children's Medical Center, School of Medicine, Shanghai Jiaotong University, Shanghai, People's Republic of \\ China: ${ }^{3}$ Shanghai Key Laboratory of Children's Environmental Health, Xinhua Hospital, School of Medicine, \\ Shanghai Jiaotong University, 1665 Kongjiang Road, Shanghai 200092, People's Republic of China
}

Submitted 18 August 2015: Final revision received 15 December 2015: Accepted 4 January 2016: First published online 24 February 2016

\begin{abstract}
Objective: We aimed to investigate the prevalence of grade 1, 2 and 3 thinness among Chinese children and to explore their associations with socio-economic status (SES).

Design: A population, school-based cross-sectional study using multistage, stratified cluster random sampling. Grade 1, 2 and 3 thinness, overweight, obesity and severe obesity were defined by the International Obesity Task Force BMI cut-offs.

Setting: Seven districts of Shanghai, China.

Subjects: Chinese children aged 3-12 years ( $n$ 84075).

Results: In boys and girls, respectively, the prevalence of grade 1 thinness was $8.89 \%$ and $11.78 \%$, of grade 2 thinness was $2.80 \%$ and $3.74 \%$, and of grade 3 thinness was $2 \cdot 23 \%$ and $2.93 \%$. Compared with urban children, suburban children had higher prevalence of thinness. Children whose parent had low education had higher prevalence of grade 1, 2 and 3 thinness than those whose parent had high education. The prevalence of grade 2 and 3 thinness, obesity and severe obesity in low-SES children was higher than that in high-SES children, and the prevalence of grade 1 thinness was lower than that in high-SES children. Particular patterns of prevalence of grade 1, 2 and 3 thinness appeared in low-, middle- and high-SES children.

Conclusions: The study describes associations of SES with grade 1, 2 and 3 thinness, overweight, obesity and severe obesity in Shanghai children. The patterns of thinness and obesity in Shanghai provide further insights into BMI patterns in mega-cities in developing countries.
\end{abstract}

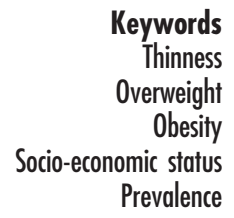

Thinness

verweight

ic status

Prevalence
Childhood obesity is an important public health issue worldwide and a growing threat to child health ${ }^{(1)}$. However, childhood thinness has received relatively less attention and fewer studies have reported the prevalence of thinness. Childhood thinness is an important indicator of malnutrition or eating disorders, which may influence cognitive development and school performance ${ }^{(2,3)}$. A few studies in the $\mathrm{UK}^{(3)}$, Australia ${ }^{(4,5)}$, Haiti ${ }^{(2)}$, Mexico ${ }^{(6)}$,

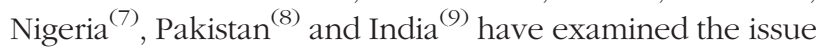
of underweight or thinness. To our knowledge, one Chinese study has included a thinness outcome. That study in Shandong Province, China, found a double

$\dagger$ Chang Chen and Zhijuan Jin contributed equally to this work. burden of overweight and thinness among children and the overall prevalence of thinness was $9.78 \%$ in boys and $15.07 \%$ in girls ${ }^{(10)}$. However, Shanghai is a mega-city; it is quite different in social conditions, economic development, health policy and historical context compared with Shandong. In view of the lack of data, thinness is worthy of attention for Shanghai children.

The association between thinness and low socioeconomic status (SES) has become less pronounced in China over the last few decades ${ }^{(11)}$. Children in low-SES families are more vulnerable to inadequate nutrition, with a greater intake of higher-energy foods and lower levels of physical activity. It is not common to find childhood obesity and malnutrition issues existing side by side ${ }^{(12)}$. 
However, different studies have found positive, negative or no correlations between SES and obesity or thinness in children, thus it is difficult to draw general conclusions $^{(13-16)}$.

Several epidemiological studies have been carried out to assess the prevalence of overweight or obesity among Shanghai children ${ }^{(17-22)}$, but there are few data about the prevalence of thinness in Chinese children. Here, we conducted a secondary analysis of data collected as part of a large cross-sectional survey of autism spectrum disorder to investigate the prevalence of grade 1,2 and 3 thinness and the comprehensive distribution of thinness, overweight and obesity among 3-12-year-old children in Shanghai. We also explored whether SES is associated with BMI in children to understand the relationship of SES with thinness better. Such information is of value in formulating effective public health policies for child health.

\section{Materials and methods}

\section{Study design and sample}

The study was a population, school-based cross-sectional study; it was part of a governmental population survey of autism spectrum disorder. We conducted multistage, stratified cluster random sampling in 3-12-year-old children across Shanghai, China in June 2014. The seventeen districts of Shanghai were stratified into eight urban in the central area and nine suburban districts in suburban areas according to the geographical and social population distribution; people living in urban and suburban districts were defined urban and suburban residents. We randomly chose three urban districts (Yangpu, Xuhui, and Jing'an) and four suburban districts (Minhang, Pudong, Fengxian and Chongming) by a random number generator. Kindergartens and elementary schools were sampled randomly from a list of schools, and the number of students recruited was chosen according to the proportion of students in each selected administrative district to the total sampled districts. In total, 134 of 949 (14.12\%) kindergartens and seventy of 436 (16.06\%) elementary schools were sampled, and 84075 of 576621 (14.58\%) children were recruited. Our study used children's family social environment and growth questionnaires. Unified and trained teachers distributed questionnaires to students, asked students to take the questionnaire home and students' parents fill in the questionnaire. The teachers collected the completed questionnaires and then returned them to the investigator. Parents offered their child's information regarding age, sex, weight, height, family income, education levels, etc. in the questionnaire by selfreport. Participants with complete weight and height data constituted the final sample.

Family income was collected in nine categories (<10 000, 10000-30000, 30000-50 000, 50 000-100 000, 100 000-150 000, $150000-200000, \quad 200000-300000$,
$300000-500000$ and >500 000 Chinese Yuan); the number of missing values for family income was 1560 (2.15\%). SES was divided into low, middle and high levels according to total family income using cut-offs of 50000 and 200000 Chinese Yuan according to the definition of social science $^{(23,24)}$. Most households comprised three persons, including two adults and one child according to the special Chinese family planning policy. Parental education was also collected, it was divided into three categories of low (illiterate, primary school and junior school), middle (high school, technical school and college) and high (undergraduate, master and doctor). Local residents were defined as those children born in Shanghai; children born in other provinces were considered the migration population.

\section{Data entry and quality control}

Data were inputted using EpiData 3.1 (EpiData Association, Odense, Denmark) and a logic error check was applied. We examined the consistency by randomly sampling $15 \%$ of the questionnaires for repeat data entry to ensure inputted data were correct.

BMI was calculated as weight divided by the square of height $\left(\mathrm{kg} / \mathrm{m}^{2}\right)$. The International Obesity Task Force definitions of thinness, overweight and obesity were used according to the centile curves of BMI cut-offs at age 18 years of respectively $18.5,17 \cdot 0$ and $16 \cdot 0 \mathrm{~kg} / \mathrm{m}^{2}$ for grades 1,2 and 3 thinness, $25 \cdot 0 \mathrm{~kg} / \mathrm{m}^{2}$ for overweight, $30 \cdot 0 \mathrm{~kg} / \mathrm{m}^{2}$ for obesity and $35.0 \mathrm{~kg} / \mathrm{m}^{2}$ for severe obesity ${ }^{(25)}$; these provide age- and sex-specific cut-off points for children aged 2-18 years. Overweight excluded obesity, and obesity excluded severe obesity.

The questionnaires were unified and anonymous and the code for each child was independent and unique. Parents were given notification and information about the investigation at the beginning of the questionnaire, to reduce non-response bias. Teachers participating in the survey underwent training so that they could give detailed instructions for filling, distribution and collection of the questionnaires to reduce bias in the study. The study was approved by the Institutional Review Boards of the Shanghai Municipal Commission of Health and Family Planning.

\section{Statistical analysis}

The prevalence of thinness, overweight and obesity was calculated directly and the $\chi^{2}$ test was performed to compare rates between boys and girls, urban and suburban groups, and low-, middle- and high-SES groups. In single variable logistic regression analysis, the odds ratio and 95\% confidence interval were determined to estimate the relative risk of thinness, overweight and obesity. Two-sided $P$ values $<0.05$ were considered statistically significant. All analyses were conducted using the statistical software package IBM SPSS Statistics Version 21. 


\section{Results}

In total 84075 questionnaires were distributed, of which 81384 completed questionnaires were returned, a response rate of $96.80 \%$. Complete data on weight and height were available for 72349 children, including 38550 boys and 33799 girls aged 3-12 years.

Table 1 shows the prevalence of grade 1, 2 and 3 thinness according to age and sex. Overall, the prevalence of thinness was $13.92 \%$ for boys and $18.45 \%$ for girls; grade 1 thinness was present in $8.89 \%$ of boys and $11.78 \%$ of girls, grade 2 thinness in $2.80 \%$ of boys and $3.74 \%$ of girls, and grade 3 thinness occurred in $2.23 \%$ of boys and $2.93 \%$ of girls (all $P<0.01$ ). Subtotal, the prevalence of grade 1, 2 and 3 thinness in boys aged 3-7 years was higher than in boys aged 7-12 years; however, the prevalence of grade 1 and 2 and total thinness in 3-7-year-old girls was lower than that in 7-12-year-old girls. There was an obvious variation in thinness by sex.

In total 44034 children were local residents and the prevalence of thinness was $12.83 \%$ for boys, $17.09 \%$ for girls; 25757 children belonged to the migration population and the prevalence of thinness was $15.50 \%$ for boys, $21.18 \%$ for girls. The prevalence of thinness in local residents was lower than that in the migration population for both boys and girls $(P<0 \cdot 01)$. Our results revealed that the prevalence of thinness decreased with age in boys, especially grade 1 thinness, while thinness in girls showed a relatively smooth prevalence. There was generally a higher prevalence of thinness in girls above 5 years of age.

Overall, in suburban and urban areas respectively, the prevalence of grade 1 thinness was $10 \cdot 18 \%$ and $9.51 \%$ $(\mathrm{OR}=1 \cdot 11 ; 95 \% \mathrm{CI} 1 \cdot 09,1 \cdot 14)$, of grade 2 thinness was $3.32 \%$ and $2.73 \%(\mathrm{OR}=1.21 ; 95 \% \mathrm{CI} 1.09,1.35)$ and of grade 3 thinness was $2.73 \%$ and $1.92 \%(\mathrm{OR}=1.42 ; 95 \%$ CI $1.25,1.61)$. Suburban children were more likely to be thin. Figure 1 shows histograms of the prevalence of grade 1, 2 and 3 thinness in boys and girls in the three urban and four suburban districts. The prevalence of grade 1 thinness in girls was significantly higher than that in boys in both urban and suburban districts (all $P<0 \cdot 01$ ). There was a significant sex difference in the prevalence of grade 2 thinness in some urban (Xuhui, $P=0.02$ ) and suburban districts (Pudong, $P<0 \cdot 01$; Minhang, $P<0 \cdot 01$ ). For grade 3 thinness, there was a significant sex difference in prevalence in one urban district (Jin'an, $P<0 \cdot 01$ ) and three suburban districts (Pudong, $P<0.01$; Minhang, $P<0.01$; Fengxian, $P=0 \cdot 04)$. There was a significant difference between overall urban and suburban districts in the prevalence of grade 1 thinness for boys $(P=0 \cdot 01)$, grade 2 thinness for girls $(P<0 \cdot 01)$ and grade 3 thinness for both boys and girls $(P<0.05)$; the prevalence of thinness in suburban districts was higher than that in urban districts.

In low-, middle- and high-SES boys (Fig. 2), the prevalence of grade 2 thinness $(3.23 \%, 2.68 \%, 2.47 \%$ ), grade
3 thinness $(2.96 \%, 1.97 \%, 1.81 \%)$, obesity $(5.99 \%, 5.56 \%$, $4.32 \%)$ and severe obesity $(3.90 \%, 3.01 \%, 2.50 \%)$ was higher in the low-SES group; however, the prevalence of grade 1 thinness $(8.29 \%, 8.92 \%, 9.82 \%)$, healthy weight $(58.47 \%, 60.37 \%, 63.08 \%)$ and overweight $(17.16 \%$, $17.48 \%, 16.00 \%)$ was higher in high-SES group. The pattern was similar in girls (Fig. 3), except that the prevalence of overweight was higher in low SES and the trend of grade 2 thinness was not obvious. Low-SES children were more likely to have grade 2 or 3 thinness, overweight and obesity, while high-SES children were more likely to have grade 1 thinness $(P<0.05)$ both in boys and girls. In the logistic regression analysis (Table 2 ), the OR for thinness was higher in low SES. For example, low-SES boys were more likely to be thin than highSES boys (grade 2 thinness: OR $=1 \cdot 55,95 \%$ CI 1.27, 1.89; grade 3 thinness: $\mathrm{OR}=2 \cdot 10$, $95 \%$ CI $1 \cdot 68,2 \cdot 63$ ). Meanwhile, parental education was a clear and consistent correlate of grade 3 thinness for boys and girls and of grade 2 thinness for boys.

\section{Discussion}

The present paper describes a large, randomly sampled, population, school-based field survey of grade 1, 2 and 3 thinness, overweight, obesity and severe obesity in the mega-city of Shanghai. Our study uniquely provided the prevalence of thinness as $15.76 \%$ for boys and $17.72 \%$ for girls aged 3-6 years in Mainland China and gives a valuable insight into thinness and obesity issues in Shanghai children. The high prevalence of overweight, obesity, severe obesity and thinness within the same group of children suggests that Shanghai is currently in the midst of a nutritional transition as the proportion of grade 2 and 3 thinness in low-, middle- and high-SES children is higher than that of severe obesity for both boys and girls (Figs 2 and 3). Hardy et al. reported that the proportion of thinness in low, middle and high SES is lower than that of obesity in both boys and girls in an Australian population $^{(26)}$. Our findings also provide evidence of substantial consistency in prevalence of thinness between urban and suburban districts, local and migrant populations, among low-, middle- and high-SES groups. The prevalence of thinness in local residents was lower than that in the migration population in both boys and girls, and the prevalence of thinness in urban districts was lower than that in suburban districts, because the proportions of local residents and high-SES children in urban districts are higher than those in suburban districts.

In our study, $16.04 \%$ of Shanghai children were thin (13.92\% for boys, $18.45 \%$ for girls). Based on the same International Obesity Task Force reference ${ }^{(27)}$, Zhang et al. reported the prevalence of thinness to be $8.72 \%$ in boys and $14.90 \%$ in girls aged $7-12$ years in Shandong Province ${ }^{(28)}$; these values are lower than the prevalence of 
Table 1 Prevalence of thinness in boys and girls aged 3-12 years ( $n 72$ 349), Shanghai, China, June 2014

\begin{tabular}{|c|c|c|c|c|c|c|c|c|c|c|c|c|c|c|c|c|c|c|c|c|c|}
\hline & \multicolumn{2}{|c|}{ Total sample } & \multicolumn{5}{|c|}{ Grade 1 thinness } & \multicolumn{5}{|c|}{ Grade 2 thinness } & \multicolumn{5}{|c|}{ Grade 3 thinness } & \multicolumn{4}{|c|}{ Total thinness } \\
\hline & \multirow{2}{*}{$\frac{\text { Boys }}{n}$} & \multirow{2}{*}{$\frac{\text { Girls }}{n}$} & \multicolumn{2}{|c|}{ Boys } & \multicolumn{2}{|c|}{ Girls } & \multirow[b]{2}{*}{$P \S$} & \multicolumn{2}{|c|}{ Boys } & \multicolumn{2}{|c|}{ Girls } & \multirow[b]{2}{*}{$P \S$} & \multicolumn{2}{|c|}{ Boys } & \multicolumn{2}{|c|}{ Girls } & \multirow[b]{2}{*}{$P \S$} & \multicolumn{2}{|c|}{ Boys } & \multicolumn{2}{|c|}{ Girls } \\
\hline & & & $n$ & $\%$ & $n$ & $\%$ & & $n$ & $\%$ & $n$ & $\%$ & & $n$ & $\%$ & $n$ & $\%$ & & $n$ & $\%$ & $n$ & $\%$ \\
\hline \multicolumn{22}{|c|}{ Age group (years) } \\
\hline $3.0-$ & 122 & 135 & 16 & $13 \cdot 11$ & 17 & $12 \cdot 59$ & 0.90 & 3 & 2.46 & 2 & 1.48 & 0.57 & 3 & $2 \cdot 46$ & 4 & 2.96 & 0.80 & 22 & 18.03 & 23 & 17.04 \\
\hline $3 \cdot 5-$ & 1057 & 950 & 135 & $12 \cdot 77$ & 117 & $12 \cdot 32$ & 0.76 & 53 & $5 \cdot 01$ & 34 & 3.58 & 0.11 & 35 & 3.31 & 37 & 3.89 & 0.48 & 223 & $21 \cdot 10$ & 188 & 19.79 \\
\hline $4.0-$ & 2228 & 2019 & 246 & 11.04 & 237 & 11.74 & 0.47 & 100 & 4.49 & 91 & 4.51 & 0.98 & 74 & 3.32 & 75 & 3.71 & 0.49 & 420 & 18.85 & 403 & 19.96 \\
\hline $4.5-$ & 2703 & 2377 & 304 & 11.25 & 287 & 12.07 & 0.36 & 67 & 2.48 & 89 & 3.74 & 0.01 & 87 & 3.22 & 79 & 3.32 & 0.83 & 458 & 16.94 & 455 & 19.14 \\
\hline $5 \cdot 0$ & 2337 & 2143 & 225 & 9.63 & 255 & 11.90 & 0.01 & 95 & 4.07 & 57 & 2.66 & 0.01 & 86 & 3.68 & 84 & 3.92 & 0.67 & 406 & 17.37 & 396 & $18 \cdot 48$ \\
\hline $5 \cdot 5-$ & 2844 & 2425 & 287 & 10.09 & 298 & $12 \cdot 29$ & 0.01 & 67 & $2 \cdot 36$ & 83 & 3.42 & 0.02 & 57 & $2 \cdot 00$ & 70 & 2.89 & 0.04 & 411 & 14.45 & 451 & 18.60 \\
\hline $6 \cdot 0-$ & 2504 & 2279 & 234 & $9 \cdot 35$ & 177 & 7.77 & 0.05 & 40 & 1.60 & 84 & 3.69 & $<0.01$ & 55 & $2 \cdot 20$ & 63 & $2 \cdot 76$ & 0.21 & 329 & $13 \cdot 14$ & 324 & $14 \cdot 22$ \\
\hline $6.5-$ & 2560 & 2189 & 210 & 8.20 & 214 & 9.78 & 0.06 & 55 & $2 \cdot 15$ & 65 & 2.97 & 0.07 & 44 & 1.72 & 53 & 2.42 & 0.09 & 309 & 12.07 & 332 & $15 \cdot 17$ \\
\hline Subtotal & 16355 & 14517 & 1657 & $10 \cdot 13$ & 1602 & 11.04 & 0.01 & 480 & 2.93 & 505 & 3.48 & 0.01 & 441 & $2 \cdot 70$ & 465 & $3 \cdot 20$ & 0.01 & 2578 & $15 \cdot 76$ & 2572 & 17.72 \\
\hline $7.0-$ & 2476 & 2082 & 201 & $8 \cdot 12$ & 225 & $10 \cdot 81$ & $<0.01$ & 88 & 3.55 & 97 & 4.66 & 0.06 & 44 & 1.78 & 70 & 3.36 & $<0.01$ & 333 & 13.45 & 392 & 18.83 \\
\hline $7 \cdot 5-$ & 2587 & 2273 & 215 & 8.31 & 298 & $13 \cdot 11$ & $<0.01$ & 65 & $2 \cdot 51$ & 83 & 3.65 & 0.02 & 55 & $2 \cdot 13$ & 74 & $3 \cdot 26$ & 0.01 & 335 & 12.95 & 455 & 20.02 \\
\hline $8.0-$ & 2515 & 2166 & 197 & 7.83 & 268 & $12 \cdot 37$ & $<0.01$ & 74 & 2.94 & 92 & 4.25 & 0.02 & 76 & 3.02 & 59 & $2 \cdot 72$ & 0.54 & 347 & 13.80 & 419 & 19.34 \\
\hline $8.5-$ & 2817 & 2495 & 230 & 8.16 & 296 & 11.86 & $<0.01$ & 74 & 2.63 & 79 & $3 \cdot 17$ & 0.24 & 73 & 2.59 & 60 & $2 \cdot 40$ & 0.66 & 377 & 13.38 & 435 & 17.43 \\
\hline $9.0-$ & 2368 & 2108 & 223 & 9.42 & 292 & 13.85 & $<0.01$ & 70 & 2.96 & 82 & 3.89 & 0.09 & 40 & 1.69 & 67 & $3 \cdot 18$ & $<0.01$ & 333 & 14.06 & 441 & 20.92 \\
\hline $9.5-$ & 2216 & 1882 & 159 & $7 \cdot 18$ & 250 & $13 \cdot 28$ & $<0.01$ & 78 & 3.52 & 85 & 4.52 & 0.10 & 31 & 1.40 & 55 & 2.92 & $<0.01$ & 268 & 12.09 & 390 & 20.72 \\
\hline $10 \cdot 0$ & 1897 & 1616 & 136 & $7 \cdot 17$ & 173 & $10 \cdot 71$ & $<0.01$ & 47 & 2.48 & 86 & 5.32 & $<0.01$ & 29 & 1.53 & 37 & $2 \cdot 29$ & 0.10 & 212 & $11 \cdot 18$ & 296 & 18.32 \\
\hline $10 \cdot 5-$ & 2187 & 1891 & 165 & 7.54 & 247 & 13.06 & $<0.01$ & 38 & 1.74 & 62 & 3.28 & $<0.01$ & 35 & 1.60 & 49 & 2.59 & 0.03 & 238 & $10 \cdot 88$ & 358 & 18.93 \\
\hline 11.0 & 1809 & 1582 & 147 & $8 \cdot 13$ & 194 & $12 \cdot 26$ & $<0.01$ & 45 & 2.49 & 48 & 3.03 & 0.33 & 17 & 0.94 & 31 & 1.96 & 0.01 & 209 & 11.55 & 273 & $17 \cdot 26$ \\
\hline 11.5 & 1323 & 1187 & 97 & 7.33 & 136 & 11.46 & $<0.01$ & 22 & 1.66 & 46 & 3.88 & $<0.01$ & 19 & 1.44 & 24 & 2.02 & 0.26 & 138 & 10.43 & 206 & 17.35 \\
\hline Subtotal & 22195 & 19282 & 1770 & 7.97 & 2379 & $12 \cdot 34$ & $<0.01$ & 601 & $2 \cdot 71$ & 760 & 3.94 & $<0.01$ & 419 & 1.89 & 526 & 2.73 & $<0.01$ & 2790 & 12.57 & 3665 & 19.01 \\
\hline Total & 38550 & 33799 & 3427 & 8.89 & 3981 & 11.78 & $<0.01$ & 1081 & $2 \cdot 80$ & 1265 & 3.74 & $<0.01$ & 860 & $2 \cdot 23$ & 991 & 2.93 & $<0.01$ & 5368 & 13.92 & 6237 & 18.45 \\
\hline
\end{tabular}

$\S P$ value from $x^{2}$ test comparing the prevalence in boys and girls. 
Table 2 Association between urbanicity, socio-economic status, parental education and thinness in boys and girls aged 3-12 years ( $n$ 72349), Shanghai China, June 2014

\begin{tabular}{|c|c|c|c|c|c|c|c|c|c|c|}
\hline \multirow[b]{2}{*}{ Sex } & \multirow[b]{2}{*}{ Factor } & \multirow[b]{2}{*}{ Category } & \multirow[b]{2}{*}{$n$} & \multirow[b]{2}{*}{$\%$} & \multicolumn{2}{|c|}{ Grade 1 thinness } & \multicolumn{2}{|c|}{ Grade 2 thinness } & \multicolumn{2}{|c|}{ Grade 3 thinness } \\
\hline & & & & & OR & $95 \% \mathrm{Cl}$ & OR & $95 \% \mathrm{Cl}$ & OR & $95 \% \mathrm{Cl}$ \\
\hline \multirow[t]{11}{*}{ Boys } & \multirow[t]{2}{*}{ District } & Urban & 8020 & 20.82 & 1.00 & Ref. & 1.00 & Ref. & 1.00 & Ref. \\
\hline & & Suburban & 30499 & $79 \cdot 18$ & $1 \cdot 13^{*}$ & $1.04,1.24$ & $1 \cdot 15$ & $0.98,1.34$ & $1.32^{*}$ & $1.10,1.58$ \\
\hline & \multirow[t]{3}{*}{ Family income } & High & 6037 & $16 \cdot 00$ & 1.00 & Ref. & 1.00 & Ref. & 1.00 & Ref. \\
\hline & & Middle & 20969 & 55.58 & 0.98 & $0.89,1.08$ & 1.18 & $0.98,1.42$ & 1.23 & $0.99,1.52$ \\
\hline & & Low & 10720 & 28.42 & 0.98 & $0.87,1.11$ & $1 \cdot 55^{*}$ & $1.27,1.89$ & $2 \cdot 10^{*}$ & $1 \cdot 68,2 \cdot 63$ \\
\hline & \multirow[t]{3}{*}{ Mother's education } & High & 9907 & $25 \cdot 86$ & 1.00 & Ref. & 1.00 & Ref. & 1.00 & Ref. \\
\hline & & Middle & 15091 & 39.38 & 1.07 & $0.97,1.17$ & $1.37^{*}$ & $1.16,1.62$ & $1.51^{*}$ & $1.24,1.85$ \\
\hline & & Low & 13319 & 34.76 & $1 \cdot 11^{*}$ & $1.01,1.22$ & $1 \cdot 79^{*}$ & $1.52,2 \cdot 12$ & $2 \cdot 58^{\star}$ & $2 \cdot 12,3 \cdot 13$ \\
\hline & \multirow[t]{3}{*}{ Father's education } & High & 11339 & 29.59 & 1.00 & Ref. & 1.00 & Ref. & 1.00 & Ref. \\
\hline & & Middle & 15316 & 39.96 & 1.03 & $0.95,1.13$ & $1.25^{*}$ & $1.07,1.46$ & $1 \cdot 75^{\star}$ & $1 \cdot 44,2 \cdot 11$ \\
\hline & & Low & 11671 & 30.45 & 1.08 & $0.98,1.18$ & $1.58^{*}$ & $1.34,1.86$ & $2 \cdot 81^{*}$ & $2 \cdot 32,3.40$ \\
\hline \multirow[t]{11}{*}{ Girls } & \multirow[t]{2}{*}{ District } & Urban & 7291 & 21.59 & 1.00 & Ref. & 1.00 & Ref. & 1.00 & Ref. \\
\hline & & Suburban & 26475 & 78.41 & $1.09^{*}$ & $1.01,1.19$ & $1.36^{*}$ & $1.17,1.58$ & $1.69^{*}$ & $1.41,2.02$ \\
\hline & \multirow[t]{3}{*}{ Family income } & High & 5507 & 16.63 & 1.00 & Ref. & 1.00 & Ref. & 1.00 & Ref. \\
\hline & & Middle & 18515 & 55.90 & 0.95 & $0.88,1.05$ & 1.00 & $0.85,1.18$ & 1.20 & $0.99,1.47$ \\
\hline & & Low & 18515 & $27 \cdot 48$ & 0.96 & $0.87,1.07$ & 1.17 & $0.98,1.40$ & $2 \cdot 10^{*}$ & $1.68,2.55$ \\
\hline & \multirow[t]{3}{*}{ Mother's education } & High & 9242 & 27.49 & 1.00 & Ref. & 1.00 & Ref. & 1.00 & Ref. \\
\hline & & Middle & 13823 & $41 \cdot 12$ & 1.02 & $0.94,1.11$ & 1.07 & $0.92,1.23$ & $1.47^{\star}$ & $1.22,1.77$ \\
\hline & & Low & 10553 & 31.39 & $1 \cdot 10^{*}$ & $1.01,1.21$ & $1.27^{*}$ & $1.09,1.47$ & $2 \cdot 88^{*}$ & $2.41,3.45$ \\
\hline & \multirow[t]{3}{*}{ Father's education } & High & 10499 & 31.23 & 1.00 & Ref. & 1.00 & Ref. & 1.00 & Ref. \\
\hline & & Middle & 13827 & $41 \cdot 17$ & 0.96 & $0.88,1.04$ & $1 \cdot 10$ & $0.96,1.26$ & $1.42^{*}$ & $1.19,1.69$ \\
\hline & & Low & 9256 & 27.56 & 1.06 & $0.97,1.16$ & $1 \cdot 20^{*}$ & $1.03,1.40$ & $2 \cdot 96^{*}$ & $2.49,3.52$ \\
\hline
\end{tabular}

Ref., reference category.

Model 1: univariate logistic regression, adjusted for age.

*Statistically significant: $P<0.05$ 


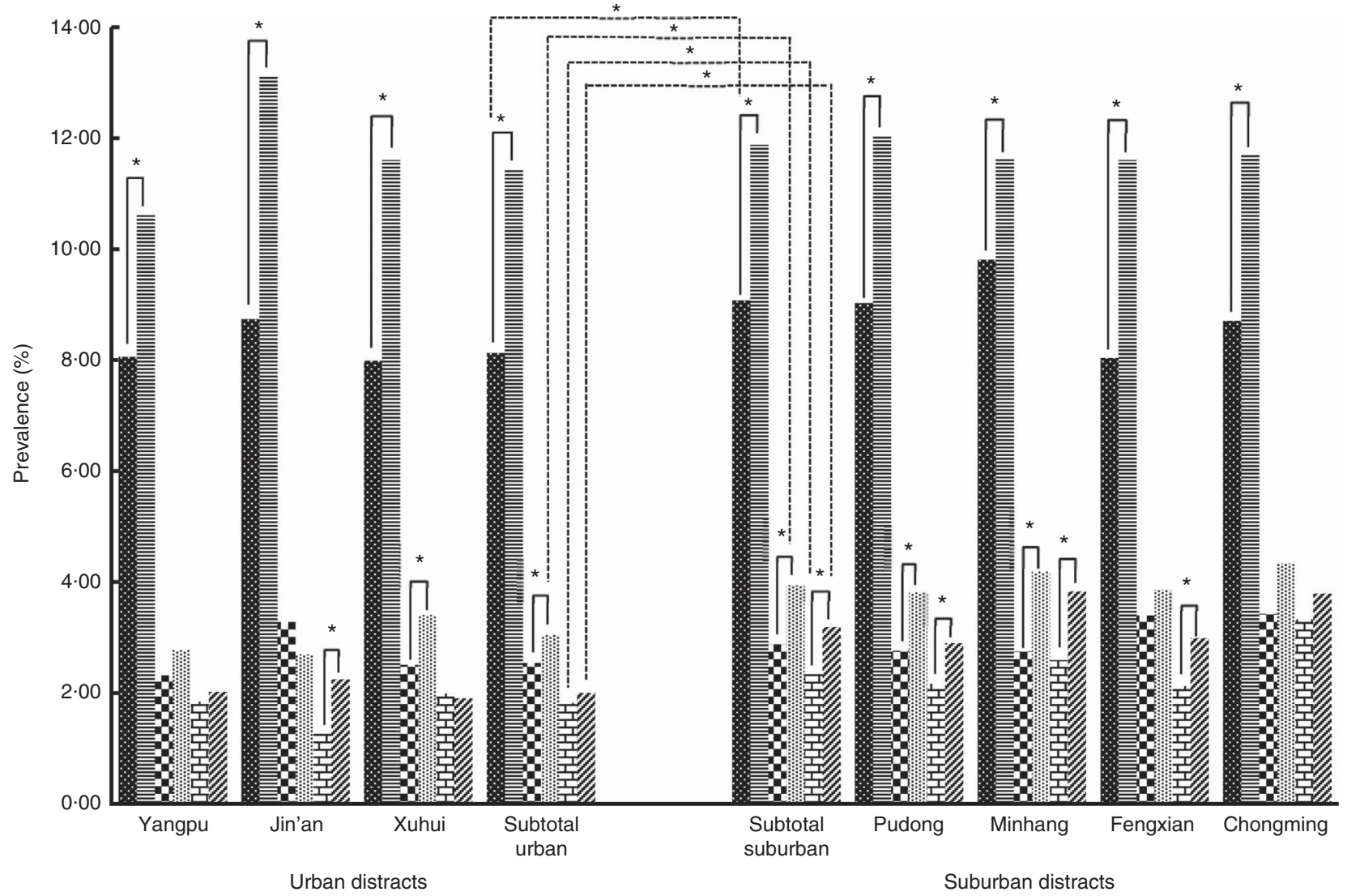

Fig. 1 Prevalence of grade 1, 2 and 3 thinness in boys and girls aged 3-12 years ( $n 72$ 349) from three urban districts (Yangpu, Jing'an, Xuhui) and four suburban districts (Pudong, Minhang, Fengxian, Chongming) in Shanghai, China, June 2014: boys with grade 1 thinness; 目, girls with grade 1 thinness; $\mathbf{D}$, boys with grade 2 thinness; 国, girls with grade 2 thinness; 回, boys with grade 3 thinness; $\mathbb{Z}$, girls with grade 3 thinness. Subtotal urban and subtotal suburban represent mean prevalence of the above three urban and above four suburban districts, respectively. ${ }^{*}$ Statistically significant difference in prevalence between boys and girls $\left(x^{2}\right.$ test): $P<0.05$

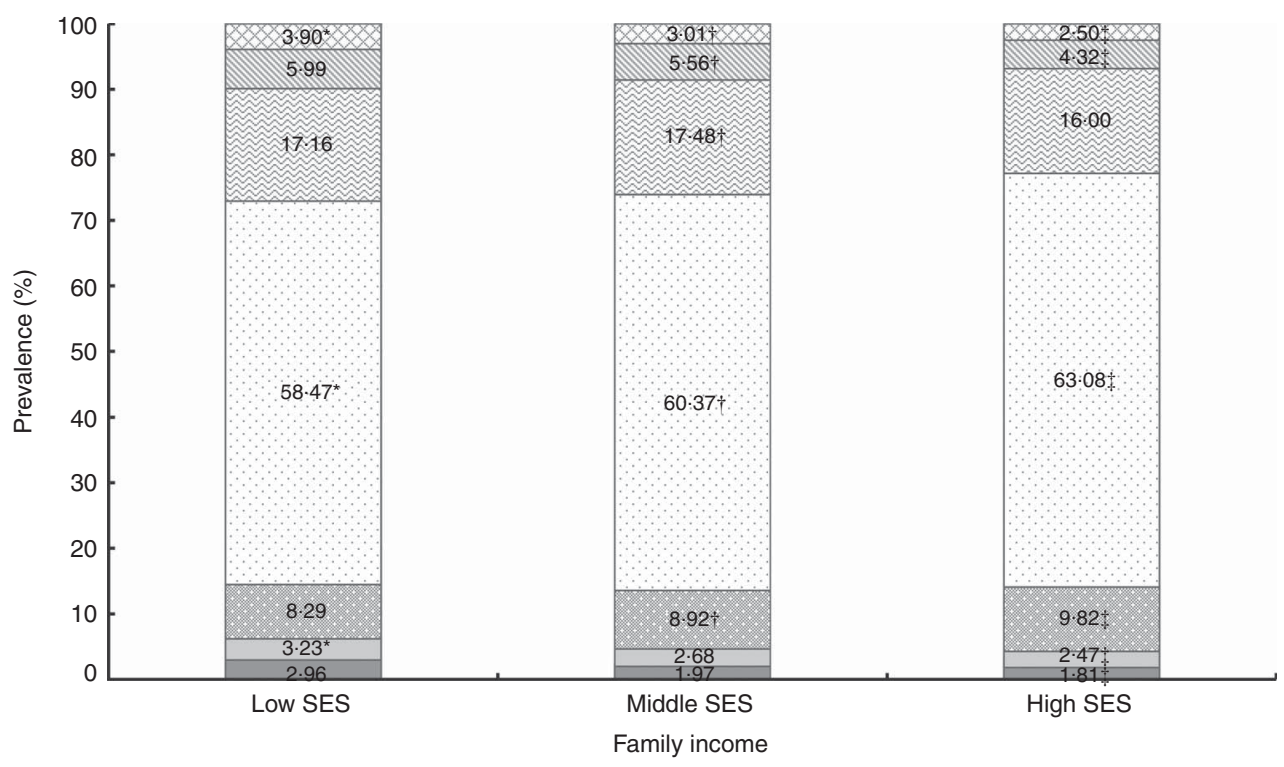

Fig. 2 Distribution of the prevalence of thinness, overweight and obesity in boys aged 3-12 years ( $n 38550$ ) of low, middle and high

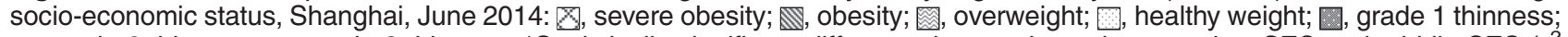
$\square$, grade 2 thinness; $\square$, grade 3 thinness. *Statistically significant difference in prevalence between low SES and middle SES $\left(x^{2}\right.$ test): $P<0.05$; †statistically significant difference in prevalence between middle SES and high SES $\left(x^{2}\right.$ test): $P<0.05 ; \neq s t a t i s t i c a l l y$ significant difference in prevalence between low SES and high SES $\left(x^{2}\right.$ test): $P<0.05$ 


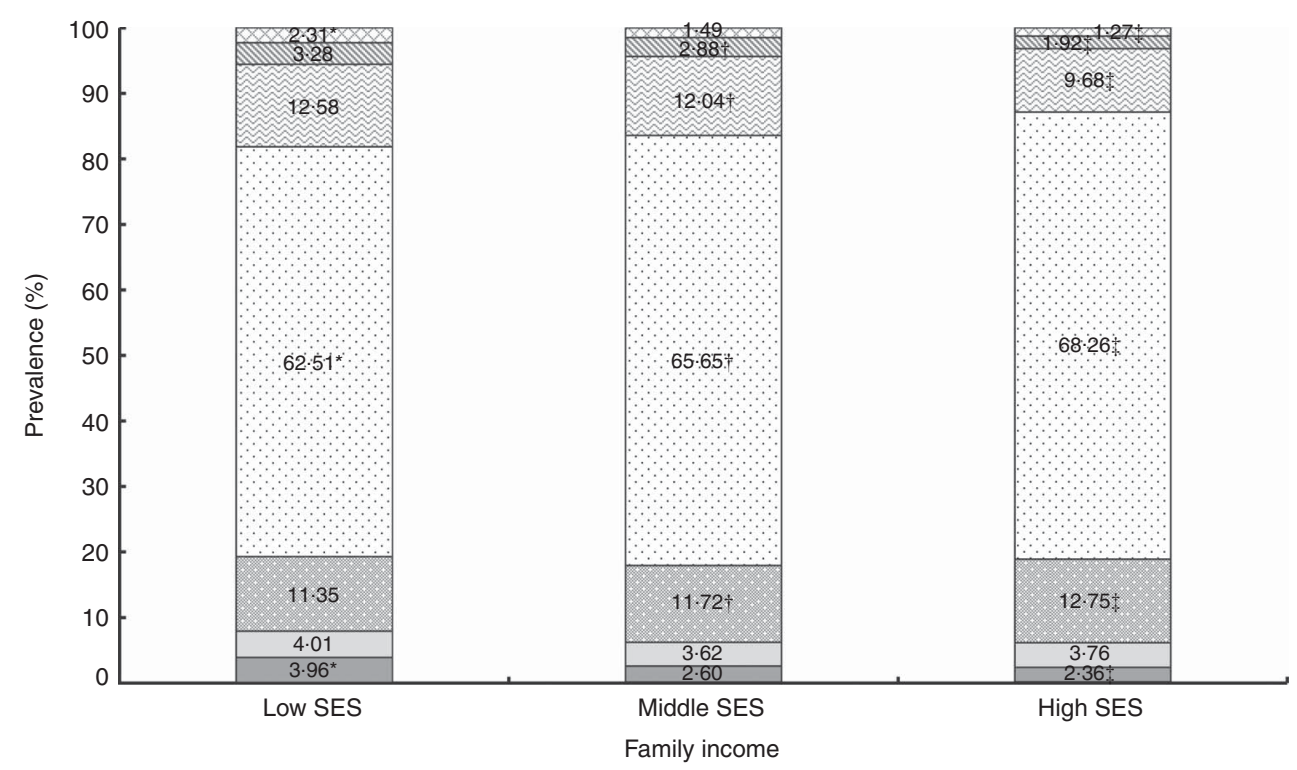

Fig. 3 Distribution of the prevalence of thinness, overweight and obesity in girls aged 3-12 years ( $n 33$ 799) of low, middle and high socio-economic status, Shanghai, June 2014: $\mathrm{X}$, severe obesity; $\mathbb{\mathbb { N }}$, obesity; 图, overweight; $\square$, healthy weight; $\square$, grade 1 thinness; $\square$, grade 2 thinness; $\square$, grade 3 thinness. *Statistically significant difference in prevalence between low SES and middle SES $\left(x^{2}\right.$ test): $P<0.05$; †statistically significant difference in prevalence between middle SES and high SES $\left(X^{2}\right.$ test): $P<0.05 ; \ddagger s t a t i s t i c a l l y$ significant difference in prevalence between low SES and high SES $\left(x^{2}\right.$ test): $P<0.05$

$12 \cdot 57 \%$ for boys and $19 \cdot 01 \%$ for girls aged $7-12$ years in present study, especially in grade 2 and 3 thinness (Table 1). The overall prevalence of thinness in our study (13.92\% for boys, $18.45 \%$ for girls) is lower than values from Hong Kong ${ }^{(29)}$ (16.7\% for boys, $22.3 \%$ for girls), India $^{(9)}\left(58.30 \%\right.$ for total) and the Seychelles ${ }^{(30)}(30 \cdot 3 \%$ for boys, $29.2 \%$ for girls); and higher than values from Australia $^{(4)}$, the Netherlands ${ }^{(31)}$, the $\mathrm{UK}^{(3)}$, Nigeria( ${ }^{(7)}$, Cameroon $^{(32)}$ and Portugal ${ }^{(33)}$. The variation may be related to differences in race, rate of urbanization, socioeconomic development and so forth.

The present study indicated that SES was significantly related to thinness in children. There was a particular SES pattern for thinness in both boys and girls. A significant negative association between SES level and prevalence of grade 3 thinness existed in our study, while SES level was positively associated with the prevalence of grade 1 thinness (Figs 2 and 3). Low-SES children were more likely to be overweight or obese than their higher-SES counterparts, and these findings were consistent with reports from Australia ${ }^{(4,13)}$ but contrasted with reports from Shandong, China ${ }^{(14)}$. The discrepancy in the results may be related to differences in the proportion of urban population between Shanghai and Shandong and variations between districts in living standards, nutritional conditions and public health policies.

There was a higher risk of grade 2 thinness, grade 3 thinness and obesity in children living in lower-SES groups. People in high-SES groups or living in urban areas are more like to have higher intakes of energy, cholesterol, protein, total fat, SFA, PUFA and MUFA, and lower intakes of carbohydrates and fibre ${ }^{(34)}$. These dietary patterns, in conjunction with inadequate physical exercise, can result in sharp increases in childhood malnutrition issues. The present study suggests that thinness is a significant issue that is overlooked. As in some other developed and developing countries around the world, China faces a double burden of thinness and overweight arising from poor nutrition. The occurrence of thinness, overweight or obesity within the same group of children has been previously reported in countries undergoing nutritional transition ${ }^{(7,35,36)}$. Therefore, it is important to face the public health challenge posed by thinness. Special attention should be paid to controlling the tendency towards a polarization of nutritional status in children.

The strengths of our study include the following: (i) it was a large, representative, multistage proportional cluster sample of children aged 3-12 years; (ii) it found a particular pattern in grade 1, 2 and 3 thinness in different SES groups; (iii) it provided a comprehensive profile of the distribution of overall BMI status including grade 1 , grade 2 , grade 3 thinness, healthy weight, overweight, obesity and severe obesity in Shanghai; and (iv) it allowed us to explore the influence of SES, parental education and urban or suburban geography. However, some limitations should be acknowledged. First, data on children's height and weight from parental reports may be inaccurate. Second, the absence of sufficient and detailed information concerning dietary patterns, physical activity and socioeconomic information at the individual level also limits our analysis. Factors related to both diet and socio-economics should be considered simultaneously in the exploration of thinness prevalence in future studies. 


\section{Conclusion}

In conclusion, the present study found a higher prevalence of grade 2 and 3 thinness, obesity and severe obesity in children from low-SES groups and children living in suburban districts. The pattern of thinness and obesity in Shanghai provides further insights into BMI patterns in mega-cities in developing countries.

\section{Acknowledgements}

Acknowledgements: The authors are grateful to all parents and teachers of the children for their assistance and cooperation in this study. Financial support: The present study was supported by the Shanghai Municipal Commission of Health and Family Planning: Shanghai Municipal Enhancing Public Health 3-year Program (2011-2013) (grant no. 11PH1951202). It had no role in the design, analysis or writing of this article. The study did not receive any other specific grant from any commercial or not-for-profit organization. Conflict of interest: All authors declare they have no conflicts of interest. Authorship: C.C. and Z.J. contributed equally to this work. X.J., Z.J. and S.L. designed the research; Z.J., H.H., F.J. and Y.Y. performed the study; C.C. and S.L. drafted the manuscript and performed statistical analyses; S.L. contributed to interpretation of the results and critically reviewed the manuscript; S.L. had primary responsibility for final content. All authors read and approved the final manuscript. Ethics of buman subject participation: This study was conducted according to the guidelines in the World Medical Association (2000) Declaration of Helsinki: Ethical Principles for Medical Research Involving Human Subjects (http://www.wma.net/en/30publications/ 10policies/b3/) and the Guidelines for the Ethical Conduct of Medical Research Involving Children, revised in 2000 by the Royal College of Paediatrics and Child Health: Ethics Advisory Committee (Arch Dis Child 2000, 82, 177-182). All procedures involving human subjects were approved by the Institutional Review Boards of the Shanghai Municipal Commission of Health and Family Planning. Verbal informed consent was obtained from all participants, and witnessed and formally recorded.

\section{References}

1. Lazzeri G, Panatto D, Pammolli A et al. (2015) Trends in overweight and obesity prevalence in Tuscan schoolchildren (2002-2012). Public Health Nutr 18 , 3078-3085.

2. Rollet SR, Gray ES, Previl H et al. (2014) Prevalence of malnutrition in children under five and school-age children in Milot Valley, Haiti. Public Health 128, 1094-1098.

3. Smith S, Craig LC, Raja EA et al. (2014) Prevalence and year-on-year trends in childhood thinness in a whole population study. Arch Dis Child 99, 58-61.
4. O'Dea JA \& Dibley MJ (2014) Prevalence of obesity, overweight and thinness in Australian children and adolescents by socioeconomic status and ethnic/cultural group in 2006 and 2012. Int J Public Health 59, 819-828.

5. Martin K, Rosenberg M, Pratt IS et al. (2014) Prevalence of overweight, obesity and underweight in Western Australian school-aged children; 2008 compared with 2003. Public Health Nutr 17, 2687-2691.

6. Malina RM, Pena-Reyes ME, Bali-Chavez G et al. (2013) Thinness, overweight and obesity in indigenous youth in Oaxaca, 1970 and 2007. Salud Publica Mex 55, 387-393.

7. Ene-Obong H, Ibeanu V, Onuoha N et al. (2012) Prevalence of overweight, obesity, and thinness among urban schoolaged children and adolescents in southern Nigeria. Food Nutr Bull 33, 242-250.

8. Mushtaq MU, Gull S, Khurshid U et al. (2011) Prevalence and socio-demographic correlates of stunting and thinness among Pakistani primary school children. BMC Public Health 11, 790.

9. Maiti S, Ghosh D \& Paul S (2011) Prevalence of thinness among early adolescent in rural school girls of Paschim Medinipur, West Bengal, India. J Trop Pediatr 57, 496-497.

10. Zhang YX, Wang ZX, Wang M et al. (2015) Prevalence of thinness among children and adolescents in Shandong, China. Eur J Nutr (Epublication ahead of print version).

11. Chen W \& Shi Z (2013) Trend in gender disparities of BMI and height between 2004 and 2011 among adolescents aged 17-18 years in Changzhou China. Asia Pac J Clin Nutr 22, 466-473.

12. Motta ME \& Silva GA (2001) Obesity and malnutrition in children: profile of a low-income community. J Pediatr (Rio J) 77, 288-293

13. O'Dea JA, Chiang H \& Peralta LR (2014) Socioeconomic patterns of overweight, obesity but not thinness persist from childhood to adolescence in a 6-year longitudinal cohort of Australian schoolchildren from 2007 to 2012. BMC Public Health 14, 222.

14. Zhang YX \& Wang SR (2012) Differences in development and the prevalence of obesity among children and adolescents in different socioeconomic status districts in Shandong, China. Ann Hum Biol 39, 290-296.

15. Gibbs BG \& Forste R (2014) Socioeconomic status, infant feeding practices and early childhood obesity. Pediatr Obes 9, $135-146$.

16. Navti LK, Ferrari U, Tange E et al. (2014) Contribution of socioeconomic status, stature and birth weight to obesity in Sub-Saharan Africa: cross-sectional data from primary school-age children in Cameroon. BMC Public Health 14, 320.

17. Li L, Shen T, Wen LM et al. (2015) Lifestyle factors associated with childhood obesity: a cross-sectional study in Shanghai, China. BMC Res Notes $\mathbf{8}, 6$.

18. Jiang XX, Hardy LL, Baur LA et al. (2014) High prevalence of overweight and obesity among inner city Chinese children in Shanghai, 2011. Ann Hum Biol 41, 469-472.

19. Lu X, Shi P, Luo CY et al. (2013) Prevalence of hypertension in overweight and obese children from a large school-based population in Shanghai, China. BMC Public Health 13, 24.

20. Hou X, Liu Y, Lu H et al. (2013) Ten-year changes in the prevalence of overweight, obesity and central obesity among the Chinese adults in urban Shanghai, 1998-2007 comparison of two cross-sectional surveys. BMC Public Health 13, 1064.

21. Zhang M, Guo F, Tu Y et al. (2012) Further increase of obesity prevalence in Chinese children and adolescents cross-sectional data of two consecutive samples from the city of Shanghai from 2003 to 2008. Pediatr Diabetes 13, 572-577. 
22. Li X, Xu J, Yao H et al. (2012) Obesity and overweight prevalence and its association with undiagnosed hypertension in Shanghai population, China: a cross-sectional population-based survey. Front Med 6, 322-328.

23. Li LY (2002) Research on the urbanization of the extramegapolis fringe and the reformation of the administrative division system in China. Econ Geogr 22, 460-466 (in Chinese).

24. Ye T (2006) Middle income and middIe income group in Shanghai. J Soc Sci 9, 91-100 (in Chinese).

25. Cole TJ \& Lobstein T (2012) Extended international (IOTF) body mass index cut-offs for thinness, overweight and obesity. Pediatr Obes 7, 284-294.

26. Hardy LL, Cosgrove C, King L et al. (2012) Shifting curves? Trends in thinness and obesity among Australian youth, 1985 to 2010. Pediatr Obes 7, 92-100.

27. Cole TJ, Flegal KM, Nicholls D et al. (2007) Body mass index cut offs to define thinness in children and adolescents: international survey. BMJ 335, 194.

28. Zhang YX, Lin M \& Sun GZ (2015) The double burden of overweight and thinness among children and adolescents in Shandong China. Int J Cardiol 184C, 380-381.

29. Mak KK, Ho SY, Lo WS et al. (2010) Health-related physical fitness and weight status in Hong Kong adolescents. BMC Public Health 10, 88.
30. Bovet P, Kizirian N, Madeleine G et al. (2011) Prevalence of thinness in children and adolescents in the Seychelles: comparison of two international growth references. Nutr J 10, 65.

31. Schonbeck Y, van Dommelen P, HiraSing RA et al. (2015) Thinness in the era of obesity: trends in children and adolescents in The Netherlands since 1980. Eur J Public Health 25, 268-273.

32. Wamba PC, Enyong Oben J \& Cianflone K (2013) Prevalence of overweight, obesity, and thinness in Cameroon urban children and adolescents. J Obes 2013, 737592.

33. Marques-Vidal P, Ferreira R, Oliveira JM et al. (2008) Is thinness more prevalent than obesity in Portuguese adolescents? Clin Nutr 27, 531-536.

34. Shang X, Li Y, Liu A et al. (2012) Dietary pattern and its association with the prevalence of obesity and related cardiometabolic risk factors among Chinese children. PLOS One 7, e43183.

35. Caleyachetty R, Rudnicka AR, Echouffo-Tcheugui JB et al. (2012) Prevalence of overweight, obesity and thinness in 9-10 year old children in Mauritius. Glob Health 8, 28.

36. Armstrong J, Dorosty AR, Reilly JJ et al. (2003) Coexistence of social inequalities in undernutrition and obesity in preschool children: population based cross sectional study. Arch Dis Child 88, 671-675. 